\title{
LA VUELTA DESDE EL LIBRO HACIA EL DIÁLOGO: EL LECTOR COMO SUJETO ACTIVO DE LA PRÁCTICA FILOSÓFICA Y LA NARRATIVA PEDAGÓGICA EN LA OBRA DE ORTEGA Y GASSET*
}

\author{
Francisco Javier Clemente Martín \\ franciscoclemente.rpf.ull@gmail.com
}

\section{RESUMEN}

En relación con la obra de Ortega y Gasset, este trabajo pretende incidir en la importancia que posee el lector en la construcción de sentido de todo texto filosófico, más allá de ese papel marginal que ha ocupado en nuestra cultura. Trataré, asimismo, de realizar un análisis crítico sobre esa perspectiva de la explicación didáctica o pedagógica hacia el lector con la que se ha interpretado tradicionalmente el factor literario de la obra orteguiana.

Palabras Clave: Ortega y Gasset, lector, literatura, discurso.

THE RETURN FROM THE BOOKTO THE DIALOGUE:

THE READER AS AN ACTIVE SUBJECT OF THE PHILOSOPHICAL PRACTICE AND THE PEDAGOGICAL NARRATIVE

IN THE WORK OF ORTEGA Y GASSET

\section{Abstract}

In relation to the work of Ortega y Gasset, this paper aims to spotlight the importance that the reader plays in the construction of meaning of all philosophical text, beyond that marginal role it has been given in our culture. I will also try to make a critical analysis about that perspective of the didactic or pedagogical explanation towards the reader with which the literary factor of Ortega's work has traditionally been interpreted.

KEYwORDs: Ortega y Gasset, reader, literature, speech. 


\section{LA "SOMBRA DEL FILÓSOFO" Y EL INTERLOCUTOR SILENCIADO ${ }^{1}$}

Pero hay que aprender a leer, como debe aprenderse a ver y a vivir. Vincent van Gogh, Cartas a Theo

La deriva canónica del pensamiento occidental ha sido, a menudo, como evidencia toda interpretación hecha desde la conciencia de sus márgenes, también una historia de perspectivas silenciadas, de desplazamientos, exilios y ocultaciones. En otro lugar ${ }^{2}$ me he referido a la condición de proscripción a la que ha sido sometida la sensibilidad literaria en el ámbito epistemológico y a la situación de olvido relativo en la que han caído ciertas tradiciones culturales e intelectuales -sea el caso, por ejemplo, del pensamiento humanista o del ensayismo hispánico- desde la perspectiva de un núcleo organizado y fuertemente institucionalizado de pensamiento hegemónico; cabría añadir otros ejemplos, como el general y sistemático olvido de las contribuciones de las mujeres al tesoro de la cultura por parte de sus exégetas e historiadores. Quiero centrarme aquí en un tipo de exclusión particularmente llamativo por cuanto tiene de inadvertido y sutil: la del lector por parte de quienes escriben textos filosóficos o, en un sentido más amplio, por parte de quienes se dedican a la comunicación filosófica. Me refiero a aquella propensión de corte mitómano que ha tenido la práctica general de la filosofía a situar al filósofo en una posición de privilegio y absoluta preponderancia con respecto al lector, a quien acostumbra a dirigirse como un interlocutor impersonal y desencarnado, de quien, con no poca frecuencia, tiende a desentenderse o, al menos, a no responsabilizarse como debiera. Lo cual resulta en una concepción de la filosofía en la que el acto propiamente filosófico termina allí donde un autor ha ofrecido un marco de pensamiento cerrado y concluso que no espera ninguna participación recíproca ni respuesta correlativa: es el autor el que propone y dice, y lo hace dentro de los límites de una organización social del conocimiento en la que el sujeto que lee queda reducido a un personaje intrascendente, mero espectador oculto entre la turba anónima del graderío ante cuya pasiva expectación la obra sigue su curso.

Ello explica, al menos parcialmente, por qué a menudo la filosofía académica vive rayana con el peligro de quedar reducida a la mera repetición de ideas y

* Trabajo cofinanciado por la Agencia Canaria de Investigación, Innovación y Sociedad de la Información de la Consejería de Economía, Industria, Comercio y Conocimiento y por el Fondo Social Europeo (FSE) Programa Operativo Integrado de Canarias 2014-2020, Eje 3 Tema Prioritario $74(85 \%)$.

${ }^{1}$ En lo sucesivo, las referencias a los textos orteguianos remitirán a José Ortega y Gasset, Obras Completas, Revista de Occidente, Madrid, 1964-1966, e irán indicadas entre paréntesis o corchetes en el propio texto mediante la abreviatura $O C$ seguida del tomo en caracteres romanos y el número de página en arábigos.

2 Véase Francisco Clemente, «El exilio de los poetas: razón vital, genus dicendi y literatura», Laguna. Revista de Filosofia, 41, 2017, pp. 73-93. 
de constituir un saber fuertemente hermetizado, cuya terminología queda blindada a cualquier tipo de comprensión no especializada. En este sentido, son ilustrativas las palabras de Martha Nussbaum apelando al olvido de "gran parte de los filósofos profesionales» de aquella concepción griega originaria de su discurso como un saber "dirigido a muchos tipos de lectores no expertos que vuelcan sus preocupaciones, sus preguntas, sus necesidades más perentorias en el texto, y cuyas almas pueden verse alteradas en el transcurso de esta interacción»" La concepción objetivista de la verdad que ha dominado nuestra cultura aborrece todo síntoma que evidencie la naturaleza del texto como "creación expresiva» dirigida a un público plural. Al querer ganar para sí un saber libre de toda contingencia -especialmente, bajo la inspiración del ideal cientificista de un conocimiento impersonal ${ }^{4}{ }^{4}$, la filosofía ha solido perder de vista al lector al que se dirigía, y, olvidándolo, el producto textual que le ofrece suele ser estéril por cuanto tiene de mecanizado e inerte, porque le impone una cierta visión del mundo en la que no cabe la participación imaginativa y empática, porque rara vez conversa vivamente con él, como cabría hacer recuperando y actualizando, hoy, el ideal del ágora, entendiendo que la labor de la filosofía ha de configurarse en un diálogo abierto y plural que no debe estar reservado exclusivamente a un público especializado y previamente adscrito a una serie de intereses muy específicos. La denuncia de Nussbaum es clara a este respecto: la prosa filosófica convencional, con sus ejemplos de corte prosaico y esquemático, tiende a carecer del atractivo estimulante y la capacidad de absorción de la buena escritura literaria $^{5}$. Su carácter cerrado y netamente expositivo, la absoluta uniformidad rítmica de su discurso - exento de cualquier accidente narrativo que contribuya a alimentar la atención del interlocutor-, su fascinación por la escritura impersonal y la terminología abstrusa suelen ser elementos que dificultan la llegada a lectores legos o con intereses ajenos al ámbito filosófico, dándoles a entender, de antemano, que se trata de un dominio de pensamiento de tipo gremial, inaccesible al individuo común y ajeno a sus motivaciones e inquietudes.

Se cumple también aquí, por tanto, aquel diagnóstico que Jauss, en el contexto de la elaboración de una estética de la recepción, atribuía a la historiografía del arte y de la literatura, solo que, quizás, con un agravante de irresponsabilidad por ubicarnos en un ámbito autoproclamado como la cuna del pensamiento crítico. Así, también la historia de la filosofía «ha sido durante demasiado tiempo la historia de los autores y de las obras», historia en la que se «reprimía o silenciaba a su "tercer componente", el lector, oyente u observador"; pero, al igual que ocurre con la función estética de una obra, las distintas expresiones del pensamiento filosófico «solo se convierten en proceso histórico concreto cuando interviene la expe-

${ }^{3}$ Martha Nussbaum, El conocimiento del amor. Ensayos sobre filosofía y literatura, Machado Libros, Madrid, 2005, p. 54.

${ }^{4}$ Cf. ibidem, p. 53.

5 Ibidem, p. 101. 
riencia de los que reciben, disfrutan y juzgan las obras» ${ }^{6}$. Hay un espacio primordial de pensamiento que se proyecta bajo aquella «sombra del filósofo» de la que nos hablaba Merleau-Ponty, bajo cuyo cobijo interpretar el pensamiento de otro consiste en hacerlo hablar a través de nuestro propio pensamiento, con nuestra voz y peculiar ademán, lo cual no indica un demérito o merma de la actividad hermenéutica, sino que describe su esencia misma y natural limitación ${ }^{7}$. Posicionados en el horizonte de incertidumbre entre lo explícitamente formulado y lo que, desde lo escrito, se proyecta hacia nuevos ámbitos de sentido, no hay término que describa más acertadamente la acometida interpretativa que el de diálogo: interpretar es dialogar, allá donde la reflexión continúa tras los puntos suspensivos que toda creación humana deja abiertos para el futuro que la acoge. «Leer es interpretar», dirá Ortega, «leer no puede consistir solo en recibir lo que buenamente las frases escritas quieren volcar sobre nosotros, [...] es forzoso salir del texto, abandonar nuestra pasividad y construirnos laboriosamente toda realidad mental no dicha en él» (OC, IX, 752). Para Paul Ricoeur, la imaginación del lector participa activamente del acto de creación emprendido en primera instancia por el escritor; más aún, dicho acto, a su juicio, solo alcanza su completitud y pleno desarrollo en el calor de la lectura, cuando el repertorio de significados que el autor ha depositado en el texto intervienen efectivamente, transformadoramente, en la narratividad vital del lector, confiriéndole herramientas con las que refigurar su propia existencia ${ }^{8}$. Se trata, al fin y al cabo, de ese mismo ejercicio de invención de lo leído que, a juicio de Fernando Savater, define en un sentido muy particular el acto de contar desde el punto de vista de quien lee: allí donde interviene la fuerza interpretativa del lector, el texto no es «el archivo de lo siempre idéntico, sino el lugar de posibilidad de lo radicalmente nuevo»?.

La lectura, pues, completa la escritura, la actualiza, la hinche de efectividad y un preciso valor de existencia, proyecta los significados primigenios hacia nuevos espacios de acción imprevistos inicialmente por el autor de una obra. Conviene, pues, que la propia consistencia estilística de un escrito -esto es, la búsqueda responsable de un ajuste apropiado entre su forma y su contenido ${ }^{10}$ - favorezca proactivamente esta interacción recíproca en la que el texto se convierte en el vaso comunicante que vincula la propuesta del autor con la vida del lector. Lo cual significa imaginar, de antemano, a este último, atraparlo y conmoverlo, apuntando, con ello, a aquella exigencia literaria que nos planteaba Ortega: «Un libro solo es bueno en la

${ }^{6}$ Hans-Robert Jauss, «El lector como instancia de una nueva historia de la literatura», en José Antonio Mayoral [coord.], Estética de la recepción, Arco libros, Madrid, 1987, p. 59.

7 Cf. Maurice Merleau-Ponty, Signos, Seix Barral, Barcelona, 1973, p. 195. Insiste el autor en que el producto resultante de la interpretación de un texto no puede reducirse ni a una mera deformación ni a una transcripción literal, pues, al tomarla así, «queremos que la significación de una obra sea solo positiva, y susceptible en derecho de un inventario que delimite lo que hay y lo que no hay en ella. Pero esto es equivocarse sobre la obra y sobre el pensar» (idem).

${ }^{8}$ Cf. Paul Ricoeur, Tiempo y Narración I, Ediciones Cristiandad, Madrid, 1987, p. 152.

9 Cf. Fernando Savater, La tarea del héroe, Ariel, Madrid, 2008, pp. 268-270.

10 Cf. Nussbaum, El conocimiento del amor, op. cit., p. 282. 
medida en que nos trae un diálogo latente, en que sentimos que el autor sabe imaginar correctamente a su lector» (OC, IV, 115). Según las palabras de Nussbaum, se trata de hacer que este "sea activo de un modo que corresponda a la comprensión de aquello que tiene que ser comprendido, con aquellos elementos que se ajusten al cometido de comprender $»^{11}$. El filósofo tiene, como indicaba Julián Marías ${ }^{12}$, una responsabilidad como escritor, contraída desde el momento en el que asume el propósito de comunicar a otros -Ortega entendió esto con claridad, probablemente gracias a su filiación periodística; y lo llamó cortesía-. Sus elecciones formales han de encaminarnos, pues, hacia «una interpretación inteligente de la vida»"

A la filosofía, relegada a un papel cada vez más marginal en nuestros planes de estudio y en el escenario de la vida pública, se le presenta hoy el reto comunicativo de combatir el desinterés, de atraer incluso a quienes jamás se ocuparon de ella y convencerles de que es relevante para sus vidas cotidianas. El texto filosófico debe, también, saber enamorar: debe conquistar al lector, sugerirle, incitarle, y ser, además, lo suficientemente abierto como para que, a su través, quepan los intereses vivos de este y su vida cobre una renovada significación. Debe, por tanto, constituir un llamamiento a la participación conjunta de pathos y logos en la lectura, reclamar la intervención de una inteligencia sentiente, y ya no de un intelecto puro y desarraigado. El problema no es baladí, pues no en vano, como señala Nussbaum, leemos "poniendo en el texto nuestras esperanzas, miedos y confusiones, y permitiendo que el texto confiera una cierta estructura a nuestros corazones» ${ }^{14}$.

\section{INTELLIGERE: SOBRE EL LEER ESFORZADO Y LA MIRADA LITERARIA}

Ortega constituye un caso especialmente interesante dentro de la historia de la filosofía porque, sin renunciar al legado de la razón y a la voluntad de que en nuestras vidas intervenga un principio de jerarquización teórica, logra romper con esa dinámica instaurada de apatía, distanciamiento y despersonalización a través de la cual el lector filosófico ha quedado generalmente relegado a un papel marginal en la actividad del pensamiento. Su obra -de forma especialmente palmaria, su obra de juventud-, como puede constatarse a través del caso ejemplar de la metáfora y de otros procedimientos de su escritura, reclama la participación implicada del interlocutor en el texto, logra estimular y alentar la lectura, generando una serie de disposiciones intelectuales y afectivas muy concretas que aquel, una vez captada su atención, se llevará consigo para evaluar su propia circunstancia. Su prosa sugerente y conmovedora, el dramatismo de sus ejemplos -en contraste con la frialdad 1973, p. 77.

11 Ibidem, p. 29.

${ }^{12}$ Cf. Julián Marías, «Ortega. Circunstancia y vocación II», Revista de Occidente, Madrid,

13 Cf. Nussbaum, El conocimiento del amor, op. cit., p. 30.

${ }^{14}$ Ibidem, p. 58. 
lógica de la que suelen valerse los recursos ejemplificativos habituales en la discursiva filosófica- ${ }^{15}$, o la recurrente presencia del mito y las figuras en sus escritos, son elementos que logran despertar en aquel un interés vivo, comparable tan solo al de la buena narrativa. Y, así, en Ortega el componente literario constituye una fuerza primordial ya no solo para la captación de problemas filosóficos, sino, también, de cara a implicar al lector activamente en la reflexión crítica y en una disposición teorizante hacia las cosas del mundo.

Martha Nussbaum defiende la tesis fundamental -que aquí asumo como principio rector de estas líneas- de que el pathos literario propicia en el lector una "conciencia agudizada", una cierta manera de ver y de percibir más intensa y atenta que la que aquel emplea en el tránsito corriente de la vida, especialmente apta para discernir entre las innumerables perspectivas que componen su realidad con un talante abierto y caritativo, capaz de hacerse cargo de la abrumadora complejidad del mundo y de la condición humana con especial delicadeza y solidaridad ${ }^{16}$. Esta consideración va en una línea absolutamente coherente con aquella exigencia que en las Meditaciones del Quijote se establecía con respecto a la lectura de un libro complejo como la gran obra cervantina: se apela allí, no a cualquier leer, sino al leer inteligente que es «intelligere» o intus-legere (OC, I, 340) ${ }^{17}$, un leer esforzado, meditativo, que sabe elegir, en el que el lector ha de emplearse por entero y en el que abrir el escorzo de la obra significa dar con aquel encuadre apropiado en el que la cosa se manifiesta y se nos hace patente. "A la lectura deslizante u horizontal, al simple patinar mental», nos dice Ortega, "hay que sustituir la lectura vertical, la inmersión en el pequeño abismo que es cada palabra, fértil buceo sin escafandra» (OC, VII,

15 Véase a este respecto ibidem, pp. 100-101.

16 «En la actividad de la imaginación literaria somos llevados a imaginar y describir con suma precisión, centrando nuestra atención en cada palabra, sintiendo cada acontecimiento con mayor intensidad; [...] gran parte de la vida real pasa sin esa conciencia agudizada, y de este modo, en cierto sentido, no se vive plena y profundamente» (ibidem, p. 102). La literatura, en fin, ofrece a sus lectores «una experiencia que es más profunda, más intensa y más precisa que gran parte de lo que tiene lugar en la vida» (idem).

17 Resulta sumamente interesante, en este sentido, la indagación etimológica llevada a cabo por Tomás Domingo Moratalla en relación con el verbo mirar como forma de profundizar en esta disposición hermenéutica que nos invita a asumir la obra orteguiana (véase Tomás Domingo MoraTALla, "Leer a ortega a la altura de nuestro tiempo», en Javier Zamora Bonilla, Guía Comares de Ortega y Gasset, Comares, Granada, 2013, pp. 334-335). El mirar que defiende Ortega está profundamente engarzado a la admiración y la maravilla, como queda patente cuando en su «Meditación preliminar» se confiesa «lleno de asombro y de ternura por lo maravilloso que es el mundo»; pero es también, nos dice Moratalla, un mirar que «nos pone a un determinado nivel de exigencia y de responsabilidad" (idem). Y es que, no se olvide, teoría -theorein- es una noción originariamente vinculada a la percepción visual: mirar atentamente, esforzadamente, contemplar. La maravilla que nace del mirar posibilita el pensamiento racional, pero solo si responde a un mirar atento y comprometido. Y, en este sentido, como señala Francisco José Martín, la capacidad de "ver más allá»-de lo establecido, de lo ordinario y consueto- es característica del lenguaje poético y requiere "esfuerzo, tesón, perseverancia, inteligencia» (Francisco José MARTín, La tradición velada. Ortega y el pensamiento humanista, Biblioteca Nueva, Madrid, 1999, p. 355). 
318). El lector tiene, también, una responsabilidad para con el texto ${ }^{18}$, correlativa a la del autor de favorecer su interés y facilitar su comprensión. En este sentido, cobra especial importancia esa peculiar virtud de la obra orteguiana de ofrecer al lector «modi res considerandi», indicaciones y sugerencias más que una visión cerrada y unívoca, evitando el pensamiento inercial y la automatización de las ideas a la que es tan propensa la prosa filosófica al uso. Aquel no se limita allí a recibir todo el trabajo reflexivo ya hecho, sino que, a través de un viaje estimulante y repleto de sentidos insinuados y abiertos, es devuelto, relanzado ${ }^{19}$, hacia su propio ámbito de acción.

Ortega, a contracorriente de cierta tradición dominante en filosofía -a buen seguro, por virtud de su filiación a un entramado de pensamiento ensayístico y periodístico habituado a hablar a un público encarnado y concreto-, asume como una de las máximas obligaciones de su pensamiento el hacerse presente al lector y tomar responsabilidad de él. De ahí aquella afirmación expresa de un propósito de «involución del libro hacia el diálogo", a través del cual se quiere ganar la conciencia del lector sobre cómo el texto se «interesa en su concreta y angustiada y desorientada humanidad» (OC, VIII, 18). En el propio reconocimiento de su circunstancia como patria de infieles en lo concerniente a la falta de habituación al pensamiento filosófico -apreciación cuyas implicaciones, no obstante, entraré a precisar en breve-, hay toda una declaración de intenciones con respecto a la importancia que Ortega concede al lector de sus textos: le preocupa que su obra sea entendida, que tenga calado entre su público, que sea el germen que promueva y propicie la tan discutida renovación cultural española. Si las cosas -en este caso, la inquietud filosófica por lo profundo y duradero- no calan en el alma patria, nos dice, es porque encuentran en esta una superficie refractaria, porque no se les ofrece un terreno favorable para germinar y crecer (OC, I, 314). Pero a nuestro alrededor prolifera el más diverso material que someter al impulso clarificador de la filosofía, «basta para ello que nos adaptemos vitalmente a él» (OC, III, 409). Estimular en el lector esa adaptación vital, ese ajuste óptico de inspiración fenomenológica por el cual las cosas de nuestro alrededor comienzan a interesarnos y hallan en nosotros un lugar propicio donde desplegar su sentido, es, en una medida significativa, lo que consiguen las peculiaridades formales que introduce Ortega en sus textos.

El caso de Meditaciones del Quijote es paradigmático a este respecto: se trata, en síntesis, de un libro que busca promover entre su público el compromiso filosó-

${ }^{18}$ Como expresa acertadamente Francisco José Martín, «las palabras escritas no hablan por sí mismas sino que necesitan que el lector les preste su voz, necesitan de la intervención de un lector que las saque de su intemporalidad y las coloque en un presente concreto y real -las palabras escritas necesitan que el lector [...] las re-viva» (Francisco José Martín, La tradición velada, op. cit., p. 338). Y es que "todo texto, conserva siempre un residuo de ilegibilidad» (ibidem, p. 339), y ninguna interpretación goza de absoluto privilegio sobre las restantes, «ninguna lectura logrará reconstruir la totalidad de sentido» (ibidem, p. 340). La lectura está siempre referida, en último término, al presente desde el que se ejecuta.

${ }^{19}$ En relación con esa capacidad de todo texto de hacer fluctuar al lector entre el mundo de la lectura y su propio ámbito de acción, véase Paul Ricoeur, Temps et récit 3. Le temps raconté, Éditions du Seuil, París, 1985, pp. 327-328. 
fico con el destino nacional dentro del escenario de la cultura europea. $Y$ este propósito se vale, primariamente, de un fortísimo componente emocional: ese proyecto de reestructuración filosófica de envergadura continental empieza, paradójicamente, con un humilde llamamiento de amor a lo inmediato, a lo que nos rodea, llamamiento a atenderlo y buscar su plenitud de significado, a auxiliarlo teóricamente, y no abandonarlo a una vida superficial y carente de propósito duradero. Desde ahí, hilvanando puntos de vista, comprendiendo que la perspectiva de lo amado se subsume, a su vez, en perspectivas más amplias (OC, I, 313), se espera que el lector alcance por sí mismo a entender la importancia de la convergencia en el destino cultural europeo. La llamada a conciencia del alma espańola para con su responsabilidad hacia Europa, la voluntad de integrar nuestro punto de vista en la vanguardia de la ciencia europea, comienza aquí estimulando en el interlocutor un cierto afán teórico movilizado desde una agudísima incitación emocional. Para Ortega es fundamental invitar a sus lectores a reproducir en ellos mismos el ejercicio de amor intelectual que propugna el libro, ofreciéndoles, a tal efecto, una cierta manera de mirar, inspirándoles una cierta disposición afectivo-comprensiva hacia la circunstancia, y este trasvase de intencionalidad filosófica se acomete apuntando al pathos del lector -sirva como ejemplo la invitación a congregarse en torno al Quijote como medio para hermanar sentimentalmente a sus potenciales lectores-.

Las emociones juegan aquí un papel crucial como agentes de implicación intelectual. No se trata ya de una exigencia elevada, en primera instancia, al estricto razonamiento del lector -en el sentido, al menos, de una ratio lógico-deductiva que opera exclusivamente bajo un principio de despersonalización metódica-; se trata de conmoverle, primero, para que ese razonamiento se movilice por sí mismo, luego, desde un irrenunciable fondo vital. Interviene aquí, por consiguiente, aquel imperativo de autenticidad que Ortega vendría a formular y desarrollar en años posteriores: aquello que no es íntimamente sentido, vivido como parte esencial de nuestro ser, difícilmente nos mueve a la acción. Pathos y logos, una vez más, operan en armonía sintética, y, en este sentido, el efecto con-movedor del lenguaje literario constituye un mecanismo irremplazable para la cristalización de esa sensibilidad responsable, empática y delicadamente perceptiva que el tipo de escritura generalmente empleado en el contexto de la práctica académica de la filosofía no consigue despertar entre buena parte de sus lectores. La dramatización de las ideas orteguianas reclama una lectura intensa y expectante, consolidando, así, un vínculo de entendimiento con el lector ${ }^{20}$.

20 Véase a este respecto Ricardo Senabre, Lengua y estilo de Ortega y Gasset, Acta Salmanticensia XVIII (3), Salamanca, 1964, p. 266 y ss. 


\section{MÁS ALLÁ DE LA INTERPRETACIÓN PEDAGÓGICA DE LA ESCRITURA ORTEGUIANA}

En este punto, conviene precisar algunas de las ideas expuestas a fin de establecer un distanciamiento con respecto a la deriva general que ha regido el análisis tradicional de estas cuestiones. Y es que, como ha insistido Francisco José Martín ${ }^{21}$, ese carácter profundamente literario del pensamiento orteguiano que aquí defiendo como un factor de primera relevancia en el plano filosófico no se ha sabido explicar, por parte de la generalidad de sus críticos y estudiosos, más allá de aquella voluntad pedagógica y regeneracionista con la que el propio Ortega se presentaba a sí mismo como un profesor de filosofía «in partibus infidelium» (OC, I, 311). En efecto, lo que con ello se pretendía expresar, siguiendo a pies juntillas las consideraciones con las que el filósofo madrileño a menudo trataba de defenderse ante cierto tipo de críticas, era la idea de que lo literario aquí -entiéndase: la escritura conmovedora, poética, personal y particularista, tan inusual en un entorno habituado a hablar con frialdad desde una perspectiva ubicua y para un público abstracto- funcionaba tan solo como un mero mecanismo de seducción motivado y justificado por la circunstancia nacional, es decir, por la necesidad de educar filosóficamente a un público no especializado, carente de formación y de general interés en el ámbito de la filosofía. Recuérdese el juicio de Ortega: en España no ha habido filosofía ni filósofos, y, a excepción del Quijote, «es, por lo menos, dudoso que haya otros libros españoles verdaderamente profundos» (OC, I, 360). Una valoración, por lo demás, probablemente no exenta de cierta exageración irónica, y, a buen seguro, injusta e inexacta, pero que apuntala, en cualquier caso, el sentido de esa perspectiva que él mismo va a sugerir para la comprensión de sus textos: la literatura constituye en ellos, en definitiva, un recurso auxiliar, de segundo orden, una licencia comunicativa subordinada al contenido teórico y destinada a hacer este más fácilmente aprehensible.

Sus palabras en diversos pasajes no dejan margen a malinterpretación: nos hablará Ortega de cómo procuró fatigosamente «ocultar la musculatura dialéctica de sus pensamientos filosóficos tejiendo sobre ella una película con color carne», es decir, «seducir hacia los problemas filosóficos con medios líricos» ante un público "que aplasta el menudo insecto de la idea [...] entre sus dedos gruesos de labriego" (OC, III, 270); aún en otro lugar, insistirá en defender esa presunta estrategia decorativa "como la naturaleza se cuida de cubrir fibra, nervio y tendón con la literatura ectodérmica de la piel», sentenciando, finalmente, que en sus textos «no se trata de algo que se da como filosofía y resulta ser literatura, sino [...] de algo que se da como literatura y resulta que es filosofía» (OC, VIII, 292-293). Estas consideraciones ilustran el afán de Ortega, puesto bajo el foco de la acusación de no ser más que un literato, por presentarnos la literariedad de su escritura como un recurso que responde a una deliberada ocultación de un núcleo de pensamiento más profundo y

${ }^{21}$ Cf. La tradición velada, op. cit., pp. 65, 124, 140 y 141. 
elemental por exigencias educativas y comunicativas ${ }^{22}$. Era como decir que su filosofía, la genuina arquitectura de su pensamiento, no alcanzaba a desplegarse plenamente ni a mostrarse de forma óptima -cabe presumir: de un modo más afín al que dictaba aquel canon ante el que se sentía recurrentemente inclinado a rendir cuentas, no sin cierto y evidente malestar- porque no quedaba otro remedio más que ofrecerla diluida en literatura ${ }^{23}$. La cual, en fin, queda así caracterizada como pretexto, licencia y simplificación, como atestigua aquella apelación a su carácter ectodérmico, por tanto, superficial, externo, que no alcanza los estratos más profundos de su propuesta filosófica. Lo literario es aquí, a la vez, límite y exigencia: es el punto en el que la filosofía entraría a asumir un juego camaleónico de ocultación y camuflaje con tal de hacerse accesible a un determinado público, movimiento en el que corría el riesgo de ser infravalorada al confundirse con una sustancia ajena y extraña, pero necesario -según se nos dice- si se quería conseguir que el lector español, hosco hacia el ideal y atenido a las superficies, se hiciera cargo filosóficamente de su realidad. Y, así, se escribe literatura tan solo para hacerle comprender más fácilmente, para incitarle y educarle, aun al precio de simplificar y esconder $-y$, con ello, de exponer abiertamente a las críticas- una verdadera filosofía oculta tras los artificios retóricos ${ }^{24}$.

Creo que hoy debemos ser críticos con este tipo de planteamientos. La observación formulada por Francisco José Martín debería constituir ya un nuevo punto de inflexión en lo concerniente a la comprensión del factor literario de los textos orteguianos: conviene erradicar esa conciencia general, tan afianzada entre sus estudiosos, de que solo merced a una licencia pedagógica puede aquel ser adecuadamente explicado. A Ortega, esta línea de defensa -que, por otra parte, es dudoso que él mismo llegara a creerse del todo, constituyendo, más bien, el testimonio más superficial de la elaboración de un personaje público- le impidió, probablemente, haber consolidado una propuesta en la que se superase de manera inequívoca la antinomia entre filosofía y literatura, y favoreció un injusto desmerecimiento de algunas de sus más lúcidas consideraciones y de algunos de sus mayores logros en el ámbito

22 Sobre las críticas orteguianas al concepto de literatura y su problemático posicionamiento en este sentido, véase lo que he expuesto en Francisco Clemente, «Sobre la condena orteguiana de la literatura: precisión y discurso 'in partibus infidelium'", Bajopalabra. Revista de Filosofía, 18, 2018, pp. 305-320.

${ }^{23}$ De ahí que, también para sus discípulos, la escritura de corte literario y, en consecuencia, el carácter abierto, disperso e inconcluso de la misma fueran, por encima de cualquier otra cosa, exigencias impuestas por el contexto. Así, por ejemplo, nos dice Julián Marías que el talante periodístico y pedagógico "ha impedido a Ortega desarrollar sus ideas muchas veces» (Ortega. Circunstancia y vocación II, op. cit., p. 82). Marías, es cierto, no niega una dimensión más profunda para esos rasgos de la escritura orteguiana (cf. ibidem, pp. 86-87); pero termina supeditándolos -y, como él, la generalidad de quienes han analizado estas cuestiones bajo la autoridad de las pautas hermenéuticas ofrecidas por el propio Ortega- a una obligación pedagógica en la que siempre se viene a poner el acento fundamental.

${ }_{24}$ Véase a este respecto Francisco José Martín, «Filosofía y literatura en Ortega», en Javier Zamora Bonilla, Guia Comares de Ortega y Gasset, op. cit., p. 183. 
de la escritura filosófica. Porque no hay allí, a despecho de lo que nos sugiere su propio autor, una filosofía que se da como literatura, sino filosofía que se da en literatura, o si se quiere, filosofía literaria, extremadamente atenta a la palabra, pero no por ello menos filosofía. Y, como sugiere el propio Francisco Martín, Meditaciones del Quijote es un texto en el que se hace especialmente evidente «el significado filosófico de los elementos retóricos que Ortega pone en juego en sus textos ${ }^{25}$-retórica que ya no constituye, como acaso entendería el sentido común, un mecanismo de persuasión fraudulenta y taimada, sino un espacio de comunión entre lo expresado y la imagen de la vida a la que rinde cuentas, y, por tanto, un espacio de pleno reconocimiento a la condición compleja de la realidad humana-.

No se ha insistido suficientemente en que el valor filosófico de la escritura orteguiana trasciende los límites de aquella narrativa de la «explicación pedagógica» que tanto se ha prodigado entre sus lectores y que ha regido la generalidad de sus interpretaciones, fundada en las estrategias diseñadas por el propio Ortega para la lectura de sus textos ${ }^{26}$. Reducir la carga literaria de su filosofía a una función meramente instructiva o didáctica supone la aceptación subrepticia de la idea de que lo literario constituye allí un elemento extraño, ajeno, espurio, fuera de lugar, cuyo uso solo puede tolerarse merced a una voluntad de pedagogía social, un pecado menor aceptable tan solo desde la consideración de sus beneficios educativos. Y, así, entre los trabajos clásicos y las líneas de investigación dominantes en el campo de los estudios orteguianos, incluso los más brillantes análisis literarios terminaban por sumarse, de un modo u otro, a la concepción de la literatura como una mera herramienta de didáctica filosófica, y, por tanto, de rebajamiento o simplificación de la teoría por requerimientos educativos ${ }^{27}$. Rindiéndose a la autoridad de este enfoque único de pensamiento, casi todos sus analistas terminaban por hablar, antes o después, acerca de cómo Ortega había venido refrenando sistemáticamente su potencial filosófico en su entrega a una responsabilidad de educación nacional, como si en un ejercicio extremo de inautenticidad hubiera estado permanentemente ocultando la plenitud de su filosofía tras una fingida $-\mathrm{y}$, a la postre, molesta y entorpe-

\footnotetext{
25 Francisco José Martín, La tradición velada, op. cit., p. 125.

${ }^{26}$ Cf. ibidem, pp. 123-125; y Francisco José Martín, «Filosofía y literatura en Ortega», op. cit., pp. 174 y 183.

27 Dejo aquí apuntadas algunas referencias en las que el lector podrá encontrar muestras más o menos representativas de esta tendencia: Julián Marías, Ortega. Circunstancia y vocación II, op. cit., pp. 18-19 y 77-79; Saturnino Álvarez, «La metáfora del «mar de dudas» en el origen del filosofar de Ortega y Gasset", Actas "Conversaciones sobre Ortega". I Jornadas Culturales, Aller, Asturias, 1983, p. 185; José LASAGA, «La madurez del filósofo: los cursos de los años treinta», en Javier ZAMORA Bonilla, Guía Comares de Ortega y Gasset, op. cit., p. 72; Ignacio Blanco, «El periodismo filosófico", en ibidem, pp. 189-190 y 198. Se repite en ellas un mismo enfoque compartido: filosofía y literatura estarían aquí, primordialmente, en una conjunción forzada por exigencias contextuales que tienen que ver con facilitar al lector - un lector pasivo, ingenuo hasta lo caricaturesco- la deglución del contenido teórico. La observación realizada a este respecto por Francisco José Martín me parece certera: «No se puede penetrar el universo orteguiano por la puerta que divide -y dividiendo falseasu escritura y su pensamiento» («Filosofía y literatura en Ortega», op. cit., p. 172).
} 
cedora- pose literaria. Pero esta concepción sirvió tan solo para fomentar la falsa expectativa y como el dolor fantasma de un texto plenario, inequívoco, la gran obra que, en rigor, nunca existió tal y como la imaginación de sus discípulos alcanzaba a entreverla oculta entre bambalinas literarias: su gran obra era la depositada en sus textos vivos, tal cual fue formulada en ellos, con todos sus defectos y su genuina forma de presentarse; era una obra amalgamada en literatura, y no una obra escondida tras literatura.

Es preciso desmitificar la consagrada explicación pedagógica, pues esta no hace justicia al verdadero potencial filosófico que atesoran los textos orteguianos. Y esto no debe malinterpretarse: desmitificarla no quiere decir negarla o anularla, tan solo desplazarla del centro y reubicarla en su relación con otros factores no menos relevantes que deben ser tomados en consideración. Mueve a Ortega, efectivamente, un innegable afán de modernización y puesta a la altura de los tiempos de la ciencia patria, y, en este sentido, la voluntad correlativa de hacerse entender, de lograr que el ejercicio teórico tuviera un calado popular ${ }^{28}$, de lograr, en suma, una institucionalización sólida del conocimiento que pusiera remedio al adanismo intelectual. Pero este ingrediente, que goza, insisto, de una irreductible porción de verdad, no acierta a explicar en toda su riqueza filosófica la vertiente poética de la escritura orteguiana, y no debe, en consecuencia, ser elevado a la condición de aval para esta última. Al decantarse por esta vía explicativa, Ortega, en cierto sentido, cayó víctima de la propia fuerza impositiva del canon, rindió cuentas ante esa racionalidad rígida que no admite extravagancias literarias, y, puesto ante su tribunal acusatorio, se justificó a través de una licencia didáctica. Pero lo cierto es que se ha sobredimensionado, magnificado esta línea hermenéutica, $y$, haciéndolo, seguramente sin pretenderlo y hasta sin desearlo, sus partidarios perpetuaban la autoridad de aquella perspectiva condenatoria concediéndole la premisa mayor: la idea de que lo literario solo podía operar allí auxiliarmente, que requería, por tanto, de una justificación previa y expiatoria. Va en demérito de los logros literarios de Ortega concebirlos como un recubrimiento bajo el cual -a pesar del cual, al margen del cual-acontece su auténtica filosofía, como el trámite artificioso que el filósofo se resigna a emplear con vistas a disciplinar la rudeza de la mente poco habituada a la reflexión filosófica. Esta idea tiene consistencia real tan solo como una cierta imagen teatral, en el

${ }^{28}$ Como señala Ignacio Blanco, «el principal objetivo de la actuación pública de Ortega fue hacerse entender, poner todo el esfuerzo en conseguir una comunicación real y efectiva con quien le escuchaba» ("El periodismo filosófico», op. cit., p. 190), y, en este sentido, es cierto que esto se traduce en cierta equidistancia entre el código del emisor y el del receptor merced al rechazo de un lenguaje iniciático (idem). El problema, sin embargo, es que el carácter literario de los textos orteguianos a menudo ha sido adscrito unilateralmente a este esfuerzo, hasta el punto de haber quedado identificado con él y confundido indistintamente con una intencionalidad puramente pedagógica, sin otra razón, propósito ni alcance. 
contexto hiperbólico de la elaboración de un personaje público que, por el hecho de serlo, entraña siempre algo de reinterpretación e irónica farsa ${ }^{29}$.

Lo que la crítica ha venido presentando innegociablemente como un deber circunstancial es, por encima de cualquier otra cosa, una firme consistencia estilística, una continuidad irreductible entre pensamiento y palabra que confiere al texto una solidez orgánica, unidad en la que el propio Ortega, después de todo, acertaba a reconocer una "tendencia incoercible» de su ser, un rasgo adscrito indeleblemente a su perspectiva y a su visión filosófica de la realidad. Solo cierto tipo muy concreto de narrativa literaria, afirma Nussbaum, «puede expresar adecuadamente ciertas verdades importantes sobre el mundo, incorporándolas en su forma y estimulando en el lector las actividades que son apropiadas para captarlas» ${ }^{30}$. El lenguaje literario alcanza a enseñarnos cosas y a infundirnos estados perceptivos que otras formas de pensamiento no consiguen hacer valer con la misma efectividad. Lo que se da en textos como Meditaciones del Quijote, renunciando al gobierno del preceptismo academicista, es, en definitiva, una refinada voluntad de estilo, una concepción del mundo que se busca en el lenguaje, que se sabe lenguaje, denodadamente esforzada por ser coherente con las palabras que emplea; una concepción que busca traspasar las fronteras de la pura comunicación informativa y aspira a conmover al lector, empaparle, disponerle a cierta mirada comprensiva y propiciar su participación esmerada. La excelencia estética se postula, aquí, como una potencia filosófica que, en ningún caso, puede concebirse como un elemento aislado, independiente o marginal ${ }^{31}$.

La belleza del texto manifiesta, patentiza su verdad ${ }^{32}$. Y esto nos devuelve a la cuestión de la importancia que adquiere el lector en el contexto de la obra orteguiana: estimular la percepción del mismo no quiere decir ya, en ese sentido extremadamente simplista que ha dominado entre la crítica, educarlo, hacer pedagogía con él; no hay aquí un sujeto sometido a una mera transformación pasiva, ingenuamente embaucado por la vía del preciosismo estético para interesarse por solemnes

${ }^{29}$ Así, por ejemplo, la literalidad de la explicación pedagógica no acierta a dar cuenta de ese paralelismo formal que subraya Julián Marías (Circunstancia y vocación II, op. cit., p. 34) entre la escritura del joven Ortega en su trabajo de tesis doctoral y la del Ortega maduro del que a menudo se ha dicho que alcanza a contener sus excesos literarios: ¡cómo se justifica, desde ese suelo, que el joven que redacta Los terrores del año mil, que no se dirige a un público general y falto de especialización, que en el contexto de un trabajo académico no se halla bajo la exigencia de hacer pedagogía con sus interlocutores, recurra a determinados recursos del lenguaje que son genuinamente definitorios de su escritura tal y como la conocemos? ¿Cómo se explica que sea Ortega, inconfundiblemente, quien allí escribe, en un texto en el que cabía limitarse a hacer Ciencia-mayúscula- sin rebajarse a la plazuela de la literatura?

${ }^{30}$ Martha Nussbaum, El conocimiento del amor, op. cit., p. 31.

31 Véase a este respecto Martha Nussbaum, Justicia poética. La imaginación literaria y la vida pública, Andrés Bello, Barcelona, 1997, p. 64.

32 «Los contenidos semánticos del pensamiento orteguiano no se nos entregan como verdades de la razón, no ponen fin a un estricto razonamiento, sino que, a través de la retorización de su discurso, nos involucran, como lectores, en el mismo proceder argumentativo» (Francisco José Martín, La tradición velada, op. cit., p. 391). 
cuestiones filosóficas en las que, de otro modo, su intelecto embrutecido no repararía; estimularlo significa, por el contrario, elevarlo a la misma condición y altura que el filósofo, propiciar su interés en pensar por sí mismo, en ser un participante crítico y comprometido de la actividad reflexiva. Ofreciéndole un discurso atractivo y sugerente, integrándolo en un diálogo vivo que apele a sus emociones y a sus intereses, el autor lanza a este una invitación a prolongar el esfuerzo de pensamiento que se le entrega en el texto como un horizonte abierto, a proyectar sobre su propia y problemática existencia los elementos reflexivos que atesora la lectura -del mismo modo que el héroe de novela, con su actitud irreverente y resuelta, nos suele inspirar el ideal de una vida más intensa y enriquecedora-; de otro modo, interponiendo entre ambos un lenguaje cerrado y blindado al interés, la comunicación peligra de fracasar. Y si algo consigue la prosa orteguiana es hacer de la filosofía un asunto atractivo y apasionante. No se trata ya de educar hacia ella por una vía amigable: el lenguaje de Ortega logra enseñarnos un mundo rico, complejo, sugerente, que solicita una mirada atenta y en el que la vida, tal y como allí se nos describe, merece la pena vivirse. 